Vegueta. Anuario de la Facultad de Geografía e Historia

21 (1), 2021, 183-211

eISSN: 2341-1112

https://doi.org/10.51349/veg.2021.1.08

\title{
Beneficio social de los ecomuseos en el territorio. El Proyecto Cultural de Desarrollo Comunitario de La Aldea como caso de estudio
}

\author{
The Social Benefit of Ecomuseums for a Territory: The Cultural \\ Community Development Project of La Aldea as a Case Study
}

\author{
Héctor Moreno Mendoza* \\ Universidad de Las Palmas de Gran Canaria \\ Instituto de Turismo y Desarrollo Económico Sostenible (TIDES) \\ https://orcid.org/0000-0001-8405-8776 \\ hectormormen@gmail.com \\ Agustín Santana Talavera \\ Universidad de La Laguna \\ Instituto Universitario de Investigación Social y Turismo \\ https://orcid.org/0000-0002-4046-0904 \\ asantana@ull.edu.es \\ Juan Manuel Parreño Castellano \\ Universidad de Las Palmas de Gran Canaria. \\ Departamento de Geografía \\ https://orcid.org/0000-0002-1082-456X \\ juan.parreno@ulpgc.es
}

Recibido: 02/07/2020; Revisado: 12/10/2020; Aceptado: 20/11/2020

\section{Resumen}

Los ecomuseos tienen el propósito de poner en valor los recursos patrimoniales de un territorio, promoviendo la conservación y la diferenciación identitaria del mismo y sus poblaciones. Se toma como caso de estudio el Proyecto Cultural de Desarrollo Comunitario de la Aldea en la isla de Gran Canaria (Islas Canarias, España), que entre sus actividades dispone de quince radiales museísticos relacionados con los oficios y labores tradicionales. A partir del análisis realizado, es posible afirmar,

*Autor de correspondencia / Corresponding author.

Copyright: (C) 2021 ULPGC. Este es un artículo de acceso abierto distribuido bajo los términos de la licencia Creative Commons Atribución-NoComercial-SinDerivar (by-nc-nd) Spain 3.0. 
Beneficio social de los ecomuseos en el territorio. El Proyecto Cultural de Desarrollo...

por una parte, que el éxito de los ecomuseos está estrechamente vinculado con su aceptación y reconocimiento por las poblaciones que lo albergan y, por otra, que de ese éxito emanan devoluciones a la población en forma de generación y conservación de vínculos sociales e identitarios.

Palabras clave: Ecomuseo, éxito social, participación, caso de estudio, desarrollo comunitario.

\begin{abstract}
The purpose of ecomuseums is to bring to light the value of a territory's patrimonial resources, promoting the conservation and distinct identity of the territory and its populations. In this article, the Cultural Community Development Project of La Aldea on the island of Gran Canaria (Canary Islands, Spain) is taken as a case study, which numbers among its activities fifteen satellite museums related to traditional trades and tasks. Based on this analysis, it is possible to state that on the one hand, the success of ecomuseums is closely tied to their acceptance and recognition by their host populations, and that on the other hand, this success entails repayment in kind to the population, by way of the generation and conservation of identity and social bonds.
\end{abstract}

Key words: Ecomuseum, Social Success, Participation, Case Study, Community Development.

\title{
1. INTRODUCCIÓN
}

En la sociedad actual, los museos locales son considerados lugares en los que el conocimiento, la gestión y el trabajo de los profesionales de esos espacios rara vez son cuestionados. Las implicaciones de los involucrados en los museos proporcionan historias reconocidas como «auténticas» en sus exposiciones, interpretaciones y actividades diversas. En otras palabras, los comisarios y los diseñadores de exposiciones pueden describir los eventos históricos y las vidas de los individuos con certeza, atendiendo a las características del lugar. Esa labor tiene el objeto de representar el pasado más o menos cercano de las poblaciones y la gente local, sus adaptaciones al territorio, la simbolización de su identidad y valores.

El ICOM (Consejo Internacional de Museos) se esfuerza por llamar la atención sobre el papel de los museos, la cultura y el patrimonio cultural en la sociedad moderna, ya que hoy en día hay comunidades que creen que pueden desarrollarse sin conciencia de su patrimonio cultural y el papel de los museos al respecto (OGNJević, 2017). En este contexto, la gestión responsable de los museos pasa a ser un elemento crucial, gestión en la que la sociedad juega un importante papel tanto por la naturaleza de los retos que deben afrontar las instituciones museísticas como por el hecho de que éstas deban generar claros beneficios sociales.

Especial mención merecen los ecomuseos, orientados a destacar la identidad de un territorio. Los ecomuseos, concepto que emerge de la llamada «nueva museología» en la década de 1970, se centran en dar soporte a la sociedad (MAGGI, 2009). Pretenden que el concepto de museo como edificio sea remplazado por la idea de «museo como lugar», en el que la naturaleza, la cultura y la historia de un lugar se pueda mostrar de un modo holístico, de tal modo que la interpretación permita que las raíces de la población local sean valoradas y entendidas (DoGAN, 
2015). Un ecomuseo (lo podríamos generalizar a cualquier infraestructura museística o patrimonial) es un instrumento que un poder público y una población, conjuntamente, conciben, fabrican y gestionan juntos. El ecomuseo será un espejo en el que esta población se mira a sí misma, para reconocerse, por el que busca una explicación sobre el territorio al que está apegada y sobre las poblaciones que la precedieron

Pero el espejo es a su vez una tarjeta de visita, en la que la población, su territorio y su historia, se presenta a sus invitados (visitantes), para ofrecerles un mejor saber con respecto a su trabajo, sus comportamientos y su intimidad (RIVIĖRE, 1985: 182). Para que esta interpretación sea coherente y el ecomuseo contribuya al desarrollo económico y social del territorio es fundamental que se base en buenos modelos de gestión (GIL, 2012). En este sentido es importante que se involucren los gestores del ecomuseo, los empleados o voluntarios de la institución, los residentes en el lugar, los visitantes y otros agentes externos que tengan un interés directo o indirecto en la buena gestión del espacio museístico. Es decir, es aconsejable que se base en un modelo de gestión participativo o comunitario.

En tanto que la rentabilidad económica en torno a los ecomuseos ha sido ampliamente estudiada, existen menos estudios sobre las fórmulas para incrementar los beneficios sociales de estas instituciones $\mathrm{y}$, menos aún, análisis de casos reales que tenga una trayectoria de funcionamiento aceptablemente eficiente en el tiempo como para enjuiciar esta cuestión.

En este contexto, se establece el objetivo principal de esta investigación, centrada en el análisis del Proyecto Cultural de Desarrollo Comunitario de La Aldea (el Proyecto, a partir de ahora), entendido como un caso exitoso de ecomuseo comunitario, que ha perdurado en el tiempo durante 40 años. El estudio se dirige a determinar cuáles son los más importantes procesos desarrollados en esta experiencia museística y los principales beneficios sociales que ha generado. Vinculado a ese objetivo principal, y atendiendo a la naturaleza de esta investigación, también se establecen dos propósitos de trabajo: por un lado, revisar las vías o propuestas para alcanzar una comunicación e implementación más eficiente, y por otro, explorar la opinión de los visitantes acerca de los beneficios que aporta este ecomuseo.

El Proyecto Cultural de Desarrollo Comunitario de La Aldea, desarrollado en este municipio del oeste grancanario, está constituido por una asociación sin ánimo de lucro, no dependiente de la financiación pública y privada, que gestiona directamente quince espacios museísticos, atestiguando diferentes aspectos relacionados con el presente, el pasado y el futuro del territorio. El proyecto estructura su oferta museística a modo de «radiales», tomando como referencia el Ecomuseu Valls d' Àneu ${ }^{1}$ (Ecomuseu Valls d' Àneu, 2020) y se compone de diferentes infraestructuras y edificios históricos repartidos a lo largo del valle de La Aldea. Dado que mantiene un modelo de gestión participativo y democrático es un ejemplo de gran interés de lo que se ha venido a llamar como ecomuseo

1 Ecomomuseu Valls d’Anéu, 2020 [en línea]. Disponible en: http://www.ecomuseu.com/es [Consulta: $02 / 07 / 2020]$. 
Beneficio social de los ecomuseos en el territorio. El Proyecto Cultural de Desarrollo...

comunitario.

Para la investigación se ha realizado observación directa, entrevistas estructuradas (a gestores del proyecto y a voluntarios), entrevistas no estructuradas (a residentes en el municipio) y encuestas a visitantes. De todo ello se obtienen datos que determinan las pautas que se han establecido en el caso de estudio, y que han servido para conseguir un desarrollo responsable, atendiendo especialmente al beneficio social que el Proyecto Comunitario de La Aldea ha generado en la población local.

Las contribuciones realizadas a partir de este análisis, limitado por tratarse de un solo caso con características socioecológicas concretas, pueden ser aplicadas a otros ecomuseos, ya tengan mayor o menor implantación temporal, sobre todo en relación con las oportunidades de desarrollo que pueden generar para la comunidad local en función de los recursos que posee el territorio. Pero no solo se pueden aplicar los resultados a los ecomuseos de gestión comunitaria, sino también pueden servir para reconocer algunos principios de funcionamiento y gestión basados en procesos de participación real en espacios con otros modelos de gestión.

\section{ECOMUSEO, BENEFICIO SOCIAL Y GESTION}

\subsection{Ecomuseo y ecomuseo comunitario}

RIVARD (1988: 123-124) estableció las diferencias entre un museo tradicional y un ecomuseo, al señalar que el museo tradicional lo forman su edificio, patrimonio, colecciones, personal experto, y visitantes, mientras que el ecomuseo lo componen el territorio, el patrimonio, la memoria colectiva y la población. El término ecomuseo surge a principios de 1970, como respuesta ante las preocupaciones de que los museos tradicionales estaban fallando en cuanto a interactuar, representar, desarrollar y sostener las comunidades locales (DAVIS, 2008).

Como definición referencia a un ecomuseo, se puede tomar la establecida en la declaración de intenciones de Long Networks. Ecomuseums and Europe, que acuerda que un ecomuseo es «una forma dinámica en que las comunidades preservan, interpretan y administran su patrimonio para un desarrollo sostenible». ${ }^{2}$

DROUGUET (2016) considera a los ecomuseos como instituciones patrimoniales inclusivas y como museos de la sociedad que integran prácticas y políticas elaboradas. Incluye entre ellos a los llamados museos de sitio, a buena parte de los museos de historia y etnografía y, en general, a los que se enfocan en hacer exhibiciones implicando la participación ciudadana. En los ecomuseos, los comisarios pierden peso en la toma de decisiones expositivas y los voluntarios o residentes ganan protagonismo.

2 Long Networks. Ecomuseums and Europe (2004). Workshop/04. Autonomous County of Trento and Ires, 2004 [en línea]. Disponible en: http://www.ecomusei.eu/mondilocali/wp-content/ uploads/2011/02/report04.pdf [Consulta: 12/06/2020]. 
El ecomuseo comunitario participa de las características propias de todo ecomuseo, pero añade otras claramente distintivas. Si no existe una definición única de ecomuseo, tampoco encontramos un concepto unívoco del comunitario (NAVAJAS CORRAL, 2019), pero podemos citar algunas características definitorias como que la iniciativa en su creación proceda de fuera de los ámbitos institucionales, frecuentemente de un grupo reducido de ciudadanos; que la gestión sea democrática y participativa; que la comunidad tenga el derecho a la toma de decisiones y que, frecuentemente, exista una sustitución del trabajo asalariado por el voluntariado, dando un carácter no lucrativo a toda la labor museística.

\subsection{Territorio, comunidad y ecomuseo comunitario}

Uno de los aspectos principales de los ecomuseos es el territorio en el que se ubican y las relaciones que los seres humanos han establecido con el mismo a través del tiempo. Se considera que el ecomuseo no es sólo el edificio (o los edificios) que han sido habilitados o construidos para contener información y objetos, sino la región misma en que se localizan, con todos sus elementos culturales y naturales. Según HUBERT (1993: 200) el ecomuseo no tiene visitantes, tiene habitantes. Asimismo, estas instituciones no están organizadas para la visita, sino para la vida; la comunidad y su territorio conforman el ecomuseo estudiándose, expresándose (Bellaigue, 1993: 129).

La relación entre los ecomuseos, el territorio y la sociedad se encuentra vinculada a la importancia de la diferenciación de historias y territorios a través de las identidades. Se trata, no tanto de marcar diferencias y similitudes con otros, sino de establecer qué elementos hacen única a una población determinada. Esas recuperaciones identitarias en un mundo global de identidades superpuestas (GONZÁLEZ-VARAS, 2015: 74), abren un proceso que requiere ensalzar el patrimonio cultural propio, combinando en ocasiones aquella motivación identitaria con la exposición al mercado turístico, que ve en el rescate y regeneración patrimonial la posibilidad de obtener réditos económicos.

Teniendo presente la variedad y el número de interrelaciones dentro de una comunidad y de esta con su territorio, la interpretación museística debe ser sistémica, considerando el patrimonio tangible, intangible y su entorno o medio ambiente (GuerRero, 2012: 101). Pero siempre existe una intervención sobre los bienes patrimoniales que están preparados para la comprensión-satisfacción del visitante. Por ese motivo, para vincularlos con el territorio, debe haber un sentido de comunidad o de identidad grupal, tanto en la construcción como en la representación.

Por ese motivo, según Giroux (2016), en el desarrollo de una política en cuanto a la colección de los ecomuseos, las áreas de experiencia que los residentes tienen sobre su propio vecindario se convierten en elementos para ser considerados sincrónicamente con la experiencia de los profesionales del museo. El proceso de identificación que rodea los elementos de la colección necesariamente se basa en 
Beneficio social de los ecomuseos en el territorio. El Proyecto Cultural de Desarrollo...

la experiencia de la comunidad y conduce a un intercambio de autoridad.

Un ecomuseo ve los edificios como objetos que cuentan una historia compartida sobre las funciones contenidas en estos edificios, sobre las personas que solían vivir en ellos y sus alrededores, y, no menos importante, el paisaje que los rodea (CLAUSEN et al., 2015). Es por lo que la interacción entre agentes, comunidad y lugares, actores y territorio, se construye mutuamente en un proceso complejo en el que se entrelazan concepciones administrativas, identitarias o constructivistas del territorio, es decir, una construcción social fomentada por la acción colectiva de los actores en el espacio geográfico.

Todo ello sólo es posible cuando contamos con comunidades con una la estructuración social propicia. Las características de estas comunidades que gestionan un proyecto cultural destacan por su singularidad, tamaño pequeño y autosuficiencia. Mantienen un modelo que, en su reproducción, asegura la continuidad social, puesto que impiden, por no necesitarlo, cualquier intercambio de información con el exterior y reafirman, por medio de la supuesta homogeneidad en el comportamiento de sus miembros, lo que los filósofos han llamado «mismidad», ${ }^{3}$ la existencia de una identificación primordial entre ellos, sólo modificada con la comunicación con el exterior, con el contacto y la información ajena a la comunidad (DELGADO, 2005)

Pero el patrimonio no solo tiene un gran potencial para contribuir al desarrollo de la identidad construida de los ciudadanos, sino que también puede desempeñar un papel fundamental en el descubrimiento de las identidades recibidas de los diferentes grupos que conforman una comunidad (SANZ y TorruelLA, 2015). Ese patrimonio debe conservarse y mostrarse también de manera legible.

Pires (2000: 193) entiende que un ecomuseo debe contar con el apoyo y la colaboración de la población y ser el resultado del deseo de esa misma población de explotar, documentar y comprender su propia evolución. Debe, incluso, llevar a la población a interesarse por su propia región, por su cultura y asumir la responsabilidad por su futuro. Pero cuando se habla de participación, no es tan sólo que la población colabore en la conformación de la exposición proporcionando información, documentos y objetos. Actualmente esos son aspectos que están contemplados en casi cualquier tipo de museo. La ecomuseología busca ir más allá, y en esto coincide con otros espacios que se inspiran en la Nueva Museología (Vergo, 1997; Ross, 2004; McCall y Gray, 2014; Boyd y Hughes, 2020). Se pretende que la creación del ecomuseo sea una decisión de la población local y que la misma participe en todas las fases de su desarrollo: la decisión e investigación de sus temáticas; el diseño del guion y su montaje; y la gestión y administración del espacio. En este escenario, es esencial que todos los ciudadanos puedan comprender las implicaciones relacionadas con la gestión adecuada del museo (Poce, 2014).

Al ofrecer el ecomuseo comunitario un modelo específico en la gestión

3 Zygmunt Bauman (2003: 19) concibe que la mismidad en la sociedad se ve en peligro en el momento en que sus condiciones empiezan a desmoronarse cuando el equilibrio entre la comunicación interna y externa, que en el tiempo pasado se inclinaba drásticamente hacia el interior, se va igualando, difuminándose así la distinción entre el «nosotros» y el «ellos». 
museística se constituye como un instrumento de autoconocimiento y un lugar para aprender y practicar regularmente habilidades y actitudes necesarias para la resolución de problemas comunitarios (FULLER, 1992: 361). En este modelo, los museos funcionan como mediadores en la transición del control de una comunidad desde quienes no son miembros de la comunidad a quienes sí lo son.

En este sentido, la participación social en el ámbito cultural y patrimonial se relaciona con nuevas lógicas de gobernanza a nivel internacional que sitúan la democratización de la gestión como un elemento fundamental de los actuales Estados. Este proceso tiene defensores, pero también acumula progresivas críticas, muy a menudo asociadas a su instrumentalización o uso parcial e interesado (Quintero y SÁnCHEZ-CARRETERO, 2017) y a la falta de profesionalidad en la gestión.

\section{METODOLOGÍA}

El propósito de este trabajo es determinar cuáles son los principales procesos desarrollados en los ecomuseos en relación con los beneficios sociales para las poblaciones en los que tienen lugar. Además, se tiene la intención de indagar en las vías o propuestas para alcanzar una comunicación e implementación más eficiente en los ecomuseos. Asimismo, se pretende explorar la opinión de los visitantes acerca de los beneficios que aportan los ecomuseos en ámbitos sociales. Es por ello que se ha determinado que es viable utilizar una estrategia de investigación cualitativa, basada en un caso de estudio concreto: El Proyecto Cultural de Desarrollo Comunitario de La Aldea (Gran Canaria, España).

La estrategia de investigación cualitativa centrada en un caso de estudio cuenta con numerosos antecedentes (Tellis, 1997; SimOns, 2011; Yin, 2017). La selección del caso se realizó, tras una revisión de los museos insulares de Gran Canaria y teniendo en cuenta que está reconocido como un referente cultural al haber sido considerado por el Comité Científico Internacional de Museos como «el museo vivo más importante de Europa» (SÁNCHEZ y SuÁREZ, 2006). Se han tomado referencias metodológicas, al menos parcialmente, siguiendo el trabajo de ADIE y Hall (2017), que realizan un análisis comparativo de tres casos de estudio de sitios culturales a través de encuestas.

Para este estudio se realizaron entrevistas estructuradas al director del proyecto, ${ }^{4}$ al cronista de La Aldea de San Nicolás ${ }^{5}$ y a 10 voluntarios que participan en el proyecto. Para tener en cuenta el punto de vista del visitante, se realizaron 100 cuestionarios (Tabla 1). La muestra en este caso estuvo determinada por la

\footnotetext{
4 Las preguntas fueron: ¿por qué se recuperan esos espacios-museos?, ¿qué motiva a los propietarios a ceder esos espacios?, ¿existen normas establecidas y acordadas?, ¿cuáles son los aspectos que determinan la cohesión de la comunidad con la perduración del proyecto?, ¿cómo se moviliza a los visitantes?, ¿cómo y dónde se publicita el proyecto?, ¿cree que se genera economía y visibilización del municipio?.

5 Las preguntas fueron: ¿qué ha significado el proyecto para el municipio?, ¿qué sucesos han determinado el surgimiento y mantenimiento del proyecto comunitario?, ¿cree que en el municipio existe cohesión social?, ¿ha colaborado el proyecto en ello?, ¿cree que es de interés político el mantenimiento del proyecto?, ¿opina que se le ha dado el apoyo suficiente desde las instituciones públicas?.
} 
Beneficio social de los ecomuseos en el territorio. El Proyecto Cultural de Desarrollo...

saturación de información (THOMAS y JAMES, 2006). ${ }^{6}$ La dirección del ecomuseo realizó además un cuestionario. ${ }^{7}$ Finalmente, se realizaron entrevistas no estructuradas -a modo de conversaciones informales- a vecinos del municipio que tenían algún tipo de negocio en la localidad. ${ }^{8}$ Toda esta información se complementó con las notas tomadas en varias visitas al proyecto.

Para analizar el contenido y proceder a la codificación de los cuestionarios a visitantes, dirección del museo y vecinos del municipio y teniendo en cuenta que las respuestas eran muy diversas dado que las preguntas eran abiertas, se establecieron ocho categorías, tomando como referencia las que establece el Laboratorio Permanente de Público de Museos (VV.AA., 2013): 1) exposición, 2) comunicación e información, 3) funcionamiento, 4) conservación, 5) instalaciones, 6) personal, 7) promoción y 8) otros.

Tanto las entrevistas estructuradas como las no estructuradas y los cuestionarios fueron complementados con la toma de notas de campo (observación directa) (PATTON, 2005; ORMSTON et al., 2014), estableciéndose de esa manera una triangulación en la toma de datos para su posterior análisis.

TABLA 1

Características de la encuesta a visitantes de los museos del Proyecto Comunitario de La Aldea

\begin{tabular}{|l|l|}
\hline Período & $29 / 7 / 2017-21 / 12 / 2017$ \\
\hline Muestreo & Aleatorio (Muestro intencional) \\
\hline Muestra final & 100 \\
\hline Sistema de recogida de datos & PAPI (en papel) \\
\hline
\end{tabular}

\footnotetext{
6 El cuestionario se compuso de 14 preguntas: 1) país de residencia, 2) tipo de alojamiento, 3) modo de llegada al museo, 4) con quién visita el museo, 5) edad, 6) género, 7) razones de la visita, 8) cómo conoció el museo, 9) ha realizado visita guiada (calidad y tiempo), 10) valoración de algunas características del museo (trato, ambiente, presentación, calidad y utilidad, aprendizaje, interés, accesibilidad, señalización, precio de las entradas, servicios, y tiempo de espera, 11) relación calidad-precio, 12) aspectos que gustaron, 13) aspectos que no gustaron y 14) sugerencias.

7 Las preguntas del cuestionario fueron sobre la propiedad, dirección, financiación, donaciones, personal y voluntariado del caso de estudio.

8 Las preguntas que se realizaron a los vecinos del municipio (principalmente propietarios de algún comercio o familiares de voluntarios del proyecto) fueron: ¿cree usted que el Proyecto genera beneficios económicos o sociales para el municipio?, ¿cuáles son las principales aportaciones que usted concibe de este proyecto?, ¿cree que el proyecto tiene sostenibilidad temporal en el municipio?, ¿cree que hubiese habido una alternativa cultural a la inexistencia del proyecto?.
} 
Héctor Moreno Mendoza, Agustín Santana Talavera y Juan Manuel Parreño Castellano

\begin{tabular}{|l|l|}
\hline \multirow{2}{*}{ Género } & Mujer $55 \%$ \\
& Hombre $44 \%$ \\
& No Contesta: $1 \%$ \\
\hline \multirow{3}{*}{ Edad } & $<18$ años: $7 \%$ \\
& $18-30$ años: $16 \%$ \\
& $31-50$ años: $37 \%$ \\
& $51-70$ años: $32 \%$ \\
& $>70$ años: $6 \%$ \\
& NC: $2 \%$ \\
\hline
\end{tabular}

Fuente: Elaboración propia.

Para realizar un análisis cualitativo realmente efectivo se requiere de una gestión de datos eficiente, coherente y sistemática (GIBBS, 2012). Para ello se ha utilizado un CAQDAS o Software de Análisis de Datos Cualitativos asistido por computadora, concretamente Nvivo 10. Un CAQDAS es una base de datos de investigación cualitativa. Los programas disponibles para ello admiten establecer registros, realizar búsquedas, efectuar análisis y acceder a los datos para examinarlos o hacer consultas. El programa tiene cinco funciones principales: 1) gestión de datos, 2) gestión de ideas, 3) encuesta a los datos, 4) modelado visual, y 5) informes.

El primer paso en Nvivo ha sido importar la información para cada uno de los casos de estudio: elementos internos (cuestionarios, entrevistas y notas observacionales) y elementos externos (tomados de las redes sociales y página web del proyecto), estos últimos con la herramienta Ncapture.

El segundo paso con Nvivo ha sido la codificación (reunir material por temas, tópico o caso) y creación de nodos (apartados que permiten recopilar información y buscar por patrones). ${ }^{9}$ Se ha codificado automáticamente basándose en patrones la información procedente de todos los recursos del caso de estudio y luego se vincularon activamente en cada proyecto todos los nodos y documentos que conforman el mismo.

El tercer paso ha sido realizar consultas y analizar palabras o frases en los recursos o nodos, como, por ejemplo, aquellas palabras que aparecen con más

9 Para la codificación de contenidos se han creado los siguientes nodos: Conservación, Interpretación, Investigación, Innovación, Difusión, Patrimonio, Institución, Estudio, Sociedad, Turismo, Equipamiento-Instalaciones, Visitantes, Gobernanza, Planificación, Valor, Intervención, Gestión, ProductoProducto turístico, Singularidad, Experiencia-Experiencial, Estrategia-Estrategias, Personal-Grupo Humano, Recurso turístico, Rentabilidad, Visitas, Accesibilidad, Presupuesto, Público, Coordinación, Gobierno, Política-Políticas, Servicio, Empresa, Modelo, Administración-Administraciones, Educativa-Educación, Promoción, Comunicación, Actor-Actores-Stakeholders, Museo, Financiación, Participación, Oferta, Experiencia, Información y La Aldea. 
Beneficio social de los ecomuseos en el territorio. El Proyecto Cultural de Desarrollo...

frecuencia. Se puede también hacer preguntas y encontrar patrones con base en la clasificación, comprobar la congruencia de las clasificaciones de los proyectos y revisar el progreso. Parte de los resultados de este análisis son presentados en este artículo.

\section{CASO DE ESTUDIO}

\subsection{Contexto geográfico y origen del Proyecto}

El proyecto surge en un contexto muy específico en el que gran parte de las razones que llevaron a su creación se fundamentan en su propia localización geográfica, en el municipio de La Aldea de San Nicolás, al oeste de la isla de Gran Canaria, situado a unos 50 Kilómetros del área turística del sur de la isla y a 63 kilómetros de la capital insular, Las Palmas de Gran Canaria (Figura 1). La primera carretera que llegó a La Aldea se construyó en 1939 desde Agaete lo que, unido a su relieve, determina un aislamiento histórico secular. Anteriormente, las comunicaciones con el exterior se realizaban por mar. Su relieve, erosionado y abrupto, está seccionado por numerosos barrancos. Su clima es seco con un paisaje semiárido, lo que ha determinado la proliferación de pequeños núcleos diseminados a lo largo del municipio buscando las zonas más húmedas y planas de los barrancos. Sus alturas están coronadas de extensos pinares (López, 2003).

El municipio contaba en 2019 con una población de 7.504 habitantes, de los que un $8,6 \%$ era extranjera, principalmente trabajadora, según las estadísticas del Padrón Continuo de Población. El municipio presentaba en el último trimestre de ese año una elevada tasa de paro registrado, del 21,13\%, según la Encuesta de Población Activa. Tradicionalmente, la base económica del municipio de La Aldea de San Nicolás ha sido la agricultura. En el pasado la producción principal era la de cereales, en especial el millo. Pero la captación de aguas ha permitido los cultivos de regadío, entre los que destaca la producción de tomate, pepinos, plantas forrajeras, papas, pimientos, berenjenas, fruta, etc. El cultivo del tomate es la principal actividad agraria del municipio en la actualidad. ${ }^{10}$ Otra actividad importante es la pesca, refugiada en su antiguo puerto, única vía de comunicación durante años de este municipio con el exterior.

10 AIDER Gran Canaria, Programa comarcal de Desarrollo Rural de Gran Canaria , 2007-2013 [en línea]. Disponible en: https://www.aidergc.com/leader/eje4leader_diagnosticosocioeconomico.pdf. [Consulta: 11/10/2020]; Cabildo de Gran Canaria: Conoce Gran Canaria-La Aldea de San Nicolás, 2018 [en línea]. Disponible en: http://cabildo.grancanaria.com/la-aldea-de-san-nicolas [Consulta: 18/06/2020]. 
Héctor Moreno Mendoza, Agustín Santana Talavera y Juan Manuel Parreño Castellano

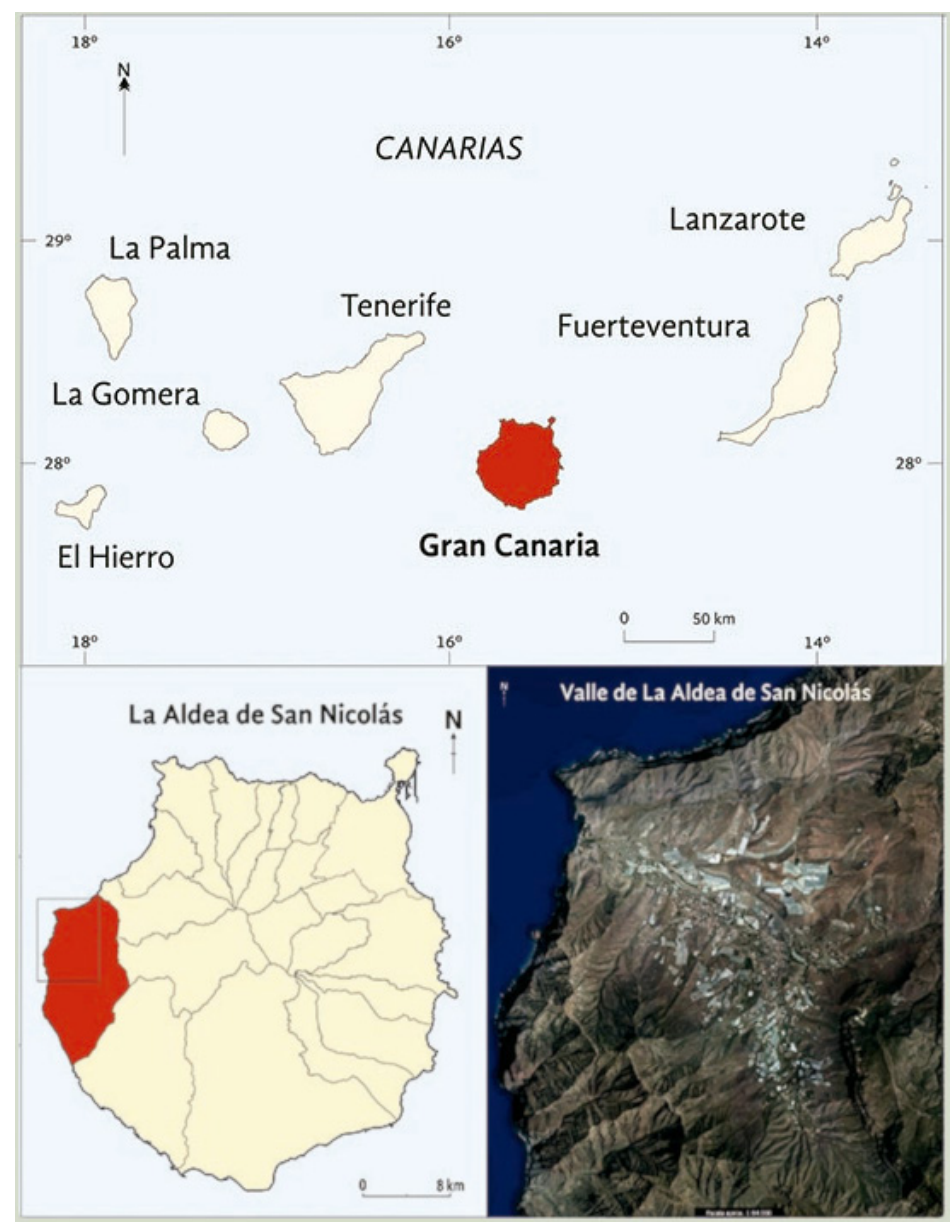

Figura 1. Mapa de localización del Proyecto Cultural de La Aldea, 2020. Fuente: GRAFCAN. Agustín Santana.

Las dificultades que han tenido que superar a lo largo de la historia la población aldeana en su lucha por la defensa de sus intereses han dado al carácter de los lugareños un alto sentido de la cooperación, como dan muestra la presencia de un desarrollado cooperativismo agrario y la realización de otras acciones colectivas como las diferentes marchas de la población aldeana hacia la capital insular en defensa de sus producciones tomateras.

La realidad cultural del municipio se centra en las Fiestas Patronales de San Nicolás, que finaliza con una romería-ofrenda. En esas fiestas destaca también La Bajada de la Rama, originaria de los aborígenes, que bajaban de la cumbre hasta el mar en tiempos de sequía para pedir lluvia. La singular Fiesta del Charco revive la costumbre del antiguo pueblo canario de embarbascar (técnica de pesca aborigen) 
Beneficio social de los ecomuseos en el territorio. El Proyecto Cultural de Desarrollo...

en los charcos costeros. A ella acuden muchos visitantes de otros municipios de la Isla. Destacan también las Fiestas del Carmen y el Carnaval, que ha recuperado los elementos tradicionales como la mascarita, los trajes viejos, las caras tapadas con un velo o un pañito de barbilla, la caña en mano y un cestito. También los niños se disfrazan con pieles de cabra y se untan manos, piernas y caras de betún, a la vez que una persona mayor hace las veces de pastor. Otras de las fiestas populares rescatadas son los Ranchos de Ánimas y de Navidad, manifestación cultural que ha sido recuperada en el municipio hace unos años, presentado en la actualidad un carácter más cercano al rancho de Pascua. Los Ranchos de Ánimas son agrupaciones musicales que se hallan enraizadas en las cofradías de ánimas de los siglos XVII y XVIII.

El legado aborigen es muy importante en el aspecto cultural de La Aldea. En el Complejo Arqueológico de Los Caserones se encontró una rica colección de pintaderas e ídolos de barro y piedra que actualmente se conservan en El Museo Canario. Actualmente se puede visitar el Túmulo Funerario del Lomo de Caserones (Playa de La Aldea). ${ }^{11}$

En este contexto geográfico, el Proyecto Cultural de Desarrollo Comunitario La Aldea comienza cuando dos maestros del Colegio Público Cuermeja, José Pedro Suárez y Lidia Sánchez, deciden incorporar la cultura popular a las actividades del centro educativo en el que trabajaban. Esto ocurrió en 1980 en la Residencia Escolar de La Aldea de San Nicolás. El objetivo inicial del Proyecto era reducir los efectos negativos que la prolongada separación de sus entornos familiares podría tener sobre algunos estudiantes. De esta manera surge una experiencia didáctica y etnográfica encomiable.

\subsection{Oferta museística}

Son diversas actividades las que conforman el Proyecto: los museos vivos, los talleres de artesanía, los deportes autóctonos, las Jornadas Anuales Regionales de Folclore, la participación en actos populares (Auto de los Reyes Magos, Rancho de Ánimas), etc. Por tanto, el Proyecto tiene un enfoque multicultural, incidiendo en la difusión de las propias tradiciones y fomentando el conocimiento mutuo y las interrelaciones culturales.

Destacan los numerosos museos vivos en los que se puede contactar con las tradiciones rurales de La Aldea: ordeñar, arar, trillar, amasar, hacer el queso, prácticas artesanales recuperadas...o visitar espacios tradicionales como una escuela rural, un almacén de tomates acompañado por el capataz, una tienda de aceite y vinagre, etc. (SÁNCHEZ et al., 2002).

Se podría considerar el Proyecto como un «museo itinerante» (BATISTA, 2009), entendiéndolo como un modelo de utilidad en cuanto al uso y gestión de los bienes culturales por el que se desarrolla un concepto disperso de museo

11 Web oficial de Turismo de Gran Canaria [en línea]. Disponible en: https://www.grancanaria.com/ turismo/es/la-isla/municipios-de-gran-canaria/sntolentino/descubre-la-aldea-de-san-nicolas/ [Consulta: 11/10/2020]. 
temático patrimonial. Es un planteamiento museístico en el que el tema es el hilo conductor de un discurso didáctico y museográfico basado en los elementos patrimoniales del territorio, incluyendo el patrimonio intangible y la población, sus protagonistas esenciales.

La red de museos se puso en marcha con La Gañanía, una finca tradicional de principios del siglo xx con estancias originales en las que se muestran las formas de vida de la cultura rural, y con el Molino de agua para moler gofio, una edificación de finales de siglo XIX que ha sido reconstruida (SÁNCHEZ et al., 2002). A continuación, se incorporaron otros museos en los que se presentan oficios y actividades tradicionales del pueblo: la Tienda, Museo de la Música, Centro Locero, la Barbería, la Escuela, el Almacén de Tomates, la Zapatería, la Medicina Rural, la Carpintería, la Herrería y la Carnicería (SuÁrez Moreno y SuÁrez Pérez, 2005). Los dos últimos espacios incorporados al Proyecto son el Museo del Pastor (2014) y el Museo de la Vestimenta Tradicional (2016).

Esta oferta se presenta mediante distintos radiales museísticos distribuidos en torno al centro urbano del municipio de La Aldea de San Nicolás (Figura 2). Se pueden realizar tres visitas o rutas distintas: una primera «corta», visitando el Molino de Gofio, el Museo del Pastor y la Gañanía, donde se pueden realizar diferentes tareas: amasar para hacer pan; hacer gofio, descamisar, desgranar, aventar, tostar o moler. Una segunda «media» donde se muestran oficios y formas de vida de antaño, visitando la Herrería, la Escuela, el Almacén de Tomates, la Tienda, la Zapatería, la Barbería, la Medicina Rural, el Centro Locero, el Museo de la Música, la Carpintería, la Carnicería y el Museo de la Vestimenta Tradicional. Se pueden ver todos o algunos museos que tengan más interés para el grupo visitante. Y una tercera «larga»: el Molino de Gofio, la Gañanía, el Museo del Pastor, la Herrería, la Medicina Rural, el Empaquetado de Tomates, la Escuela, la Barbería, la Carpintería, la Zapatería, el Centro Locero, el Museo de la Música, la Tienda, la Carnicería y el Museo de la Vestimenta Tradicional. Esta ruta también es configurable en cuanto a espacios. 
Beneficio social de los ecomuseos en el territorio. El Proyecto Cultural de Desarrollo...

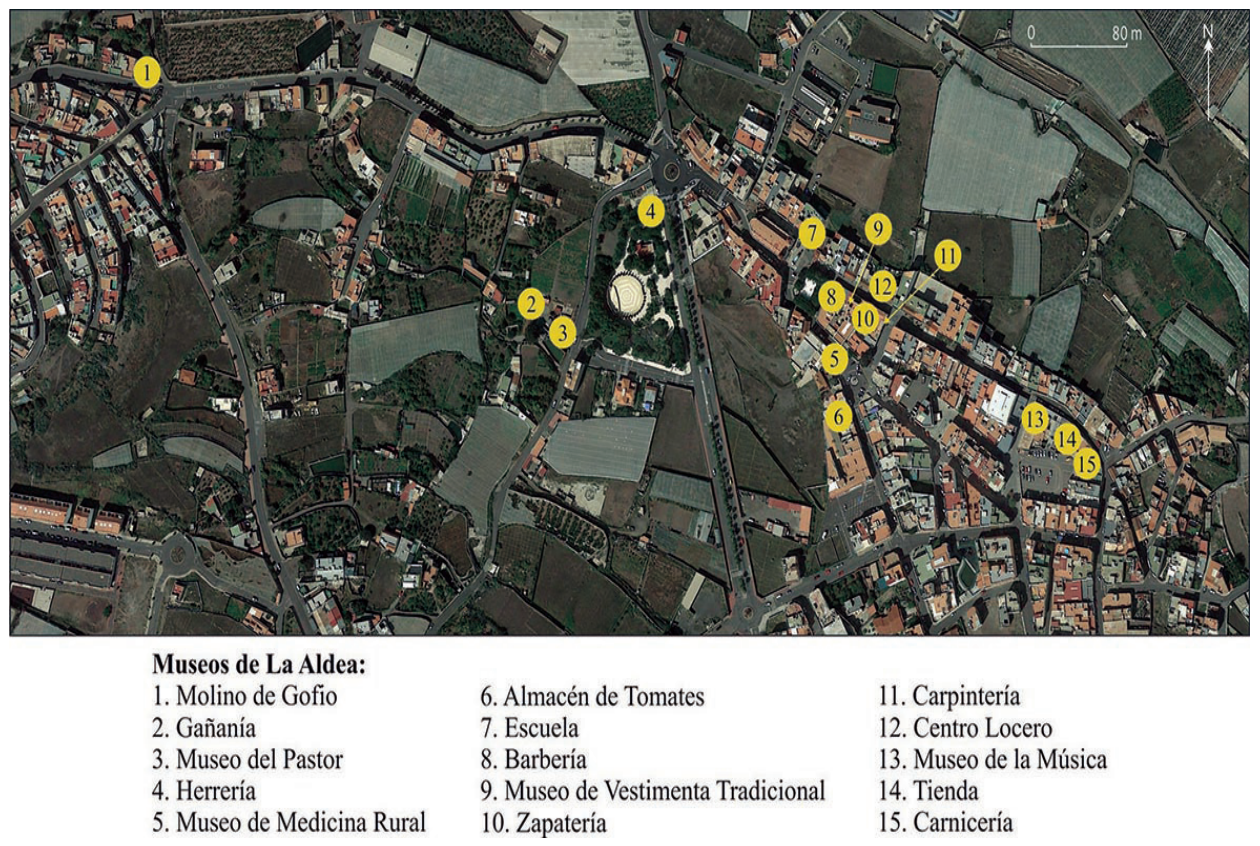

Figura 2. Mapa de localización de los museos del Proyecto. Fuente: Agustín Santana, 2020.

\section{ANÁLISIS DEL PROYECTO CULTURAL DE DESARROLLO COMUNITARIO DE LA ALDEA}

A partir del análisis realizado, se presentan diferentes resultados referentes a la gestión del museo, la labor de promoción online que se realiza, los beneficios sociales que genera y la visión que tienen los visitantes del mismo.

\subsection{El modelo de gestión}

La recuperación de los espacios-museos (Figura 3) se ha realizado después de un trabajo de campo realizado desde la escuela por el que se fueron recuperando oficios tradicionales y modos de vida del mundo rural de La Aldea. Todo este trabajo de rescate patrimonial se fue reflejando, a través de los años, en los diferentes espacios museísticos, ayudado por los propios informantes, que como voluntarios explican de primera mano todo lo que acontece dentro de los museos. No obstante, en un primer momento, se realizaban sólo actividades en el campo del folclore musical y luego se extendieron a otras relacionadas con las tradiciones y formas de vida de la sociedad histórica reciente.

Aunque durante mucho tiempo el Proyecto no se sostuvo mediante ninguna fórmula asociativa, hace un tiempo está soportado por una asociación sin ánimo de 
lucro, dirigida por una asamblea coordinada por un presidente, un vicepresidente, un tesorero, un secretario y un vocal. La asamblea es la forma de gobierno en el Proyecto. Los cargos directivos son asignados mediante propuestas. Se realizan votaciones para tomar decisiones. Hay un estatuto y una memoria de asociación. Las decisiones se toman en la asamblea, mediante consenso o voto directo o delegado de todos los asociados. Tal implicación social en la gestión del ecomuseo es precisamente lo que le caracteriza y diferencia de otras formas museísticas o de presentación patrimonial a este Proyecto.

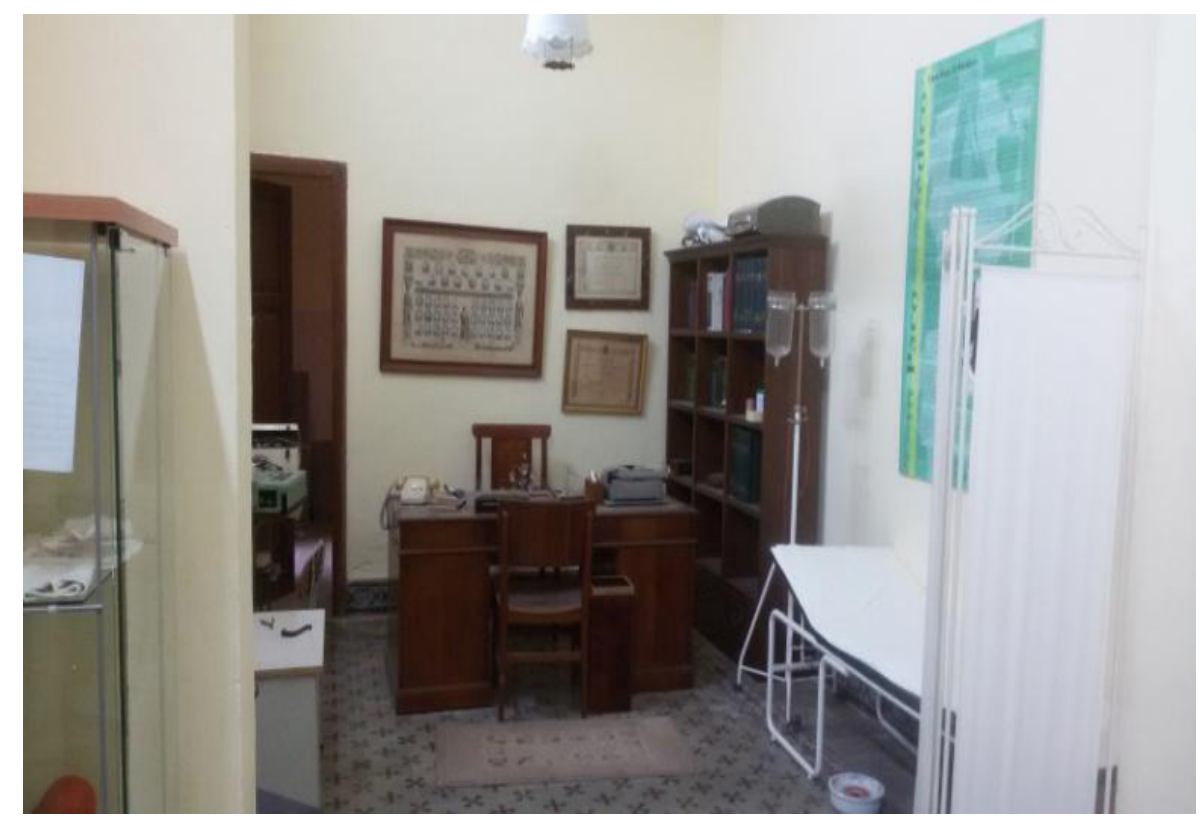

Figura 3. Museo de la Medicina Rural. Fotografía: Héctor Moreno, 2018.

Los ingresos anuales de la asociación (unos $15.000 €$ en 2019) proceden de una subvención de la Fundación para la Etnografía y Desarrollo de la Artesanía Canaria (FEDAC), que es una fundación autónoma perteneciente al Cabildo de Gran Canaria. Las actividades se ofrecen de manera gratuita, así que, salvo donaciones y otras subvenciones públicas, el Proyecto no cuenta con más ingresos. Las donaciones públicas son bien valoradas dado que no implica su aceptación ninguna dificultad administrativa.

La mayoría de los espacios museísticos son cesiones temporales al Proyecto basadas principalmente en acuerdos verbales, sin contratos legales. Junto a estos espacios cedidos de propiedad privada, la asociación tiene también el uso de otros dos de titularidad pública, el Molino de Agua y la Herrería. 
Beneficio social de los ecomuseos en el territorio. El Proyecto Cultural de Desarrollo...

Las cesiones se fundamentan en un ambiente de confianza mutua entre los propietarios y el director del Proyecto, por la que los primeros pueden recuperar sus propiedades desde el momento en que lo soliciten. Los voluntarios evitan en la medida de los posible que se generen problemas legales y nunca se ha pedido un documento firmado, todo funciona de palabra. Las únicas normas establecidas por los propietarios es que se conserve y se mejoren los espacios cedidos y que el Proyecto se haga cargo de los gastos comunes como el IBI, el consumo de agua, luz, etc. Esos gastos normalmente se financian a través de las subvenciones y ayudas con las que cuenta el Proyecto.

El Proyecto ha contado con el apoyo de la Consejería de Educación, especialmente desde los noventa, momento en que liberó a los dos maestros que impulsaron el Proyecto para que se dedicaran exclusivamente a este. La administración les ha concedido subvenciones oficiales y ha apoyado, particularmente, las jornadas de folclore que llevan celebrándose casi 30 años. Sin embargo, estas subvenciones son variables en el tiempo y en sus cuantías. De hecho, las ayudas públicas no han sido suficientes y por ejemplo no ha colaborado en el pago de los alquileres de los inmuebles, cuando se ha tenido que recurrir a esta fórmula o el coste de su mantenimiento.

En cuanto al personal, el número de implicados en el Proyecto es de 45 voluntarios. Sin embargo, para algunos actos se superan los 200 participantes. No se retribuye trabajo alguno, lo que supone una menor complejidad en la gestión. De hecho, todos los entrevistados opinan que no se tendría que profesionalizar el Proyecto, y que, si esto llegara a pasar, dejarían de participar en el mismo. No hay beneficios económicos personales, las personas funcionan con un interés más filántropo.

De aquí se deduce que una buena gestión del ecomuseo debe implicar desarrollar estrategias que impliquen a un mayor número de personas de la población local, lo que supondría un incremento en el número de voluntarios.

Los integrantes del Proyecto han debatido varias veces la creación de una cooperativa que cobrase por realizar otros servicios (como servir comidas o vender suvenires) pero no se ha dado el paso aún. Todos creen que la entrada a los museos debe seguir siendo gratuita pero que sería conveniente involucrar a agentes privados (empresas) para la mejora de algunas actuaciones a largo plazo en las acciones museísticas o radiales.

\subsection{Promoción y visibilidad online}

El Proyecto utiliza diferentes modos para promocionarse. Se difunde a través de páginas webs y redes sociales. En concreto, cuenta con una página web propia (Figura 4) y es promocionado a través del portal online de la Consejería de Educación del Gobierno de Canarias, dado que la mayoría de los visitantes provienen de centros de enseñanza de diversos niveles educativos, la página web del Cabildo Insular de Gran Canaria (a través de la Consejería de Cultura) y la página web del Ayuntamiento de La Aldea. La difusión a través de redes 
sociales, como Facebook (Figura 5), Twitter o YouTube (Figura 6) está orientada a la promoción del Proyecto entre otros colectivos. Además, el Proyecto cuenta con folletos divulgativos, aunque sólo en español.

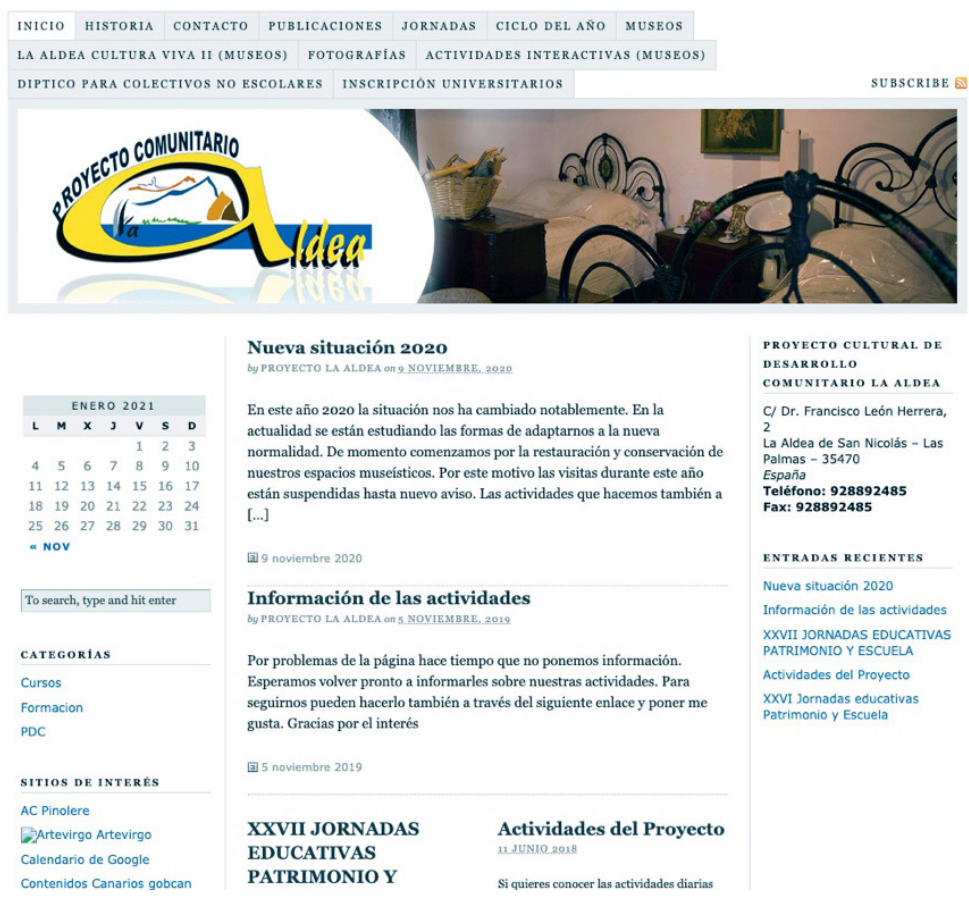

Figura 4. Web del Proyecto Comunitario Aldea [en línea]. Disponible en: www. proyectolaaldea.com 


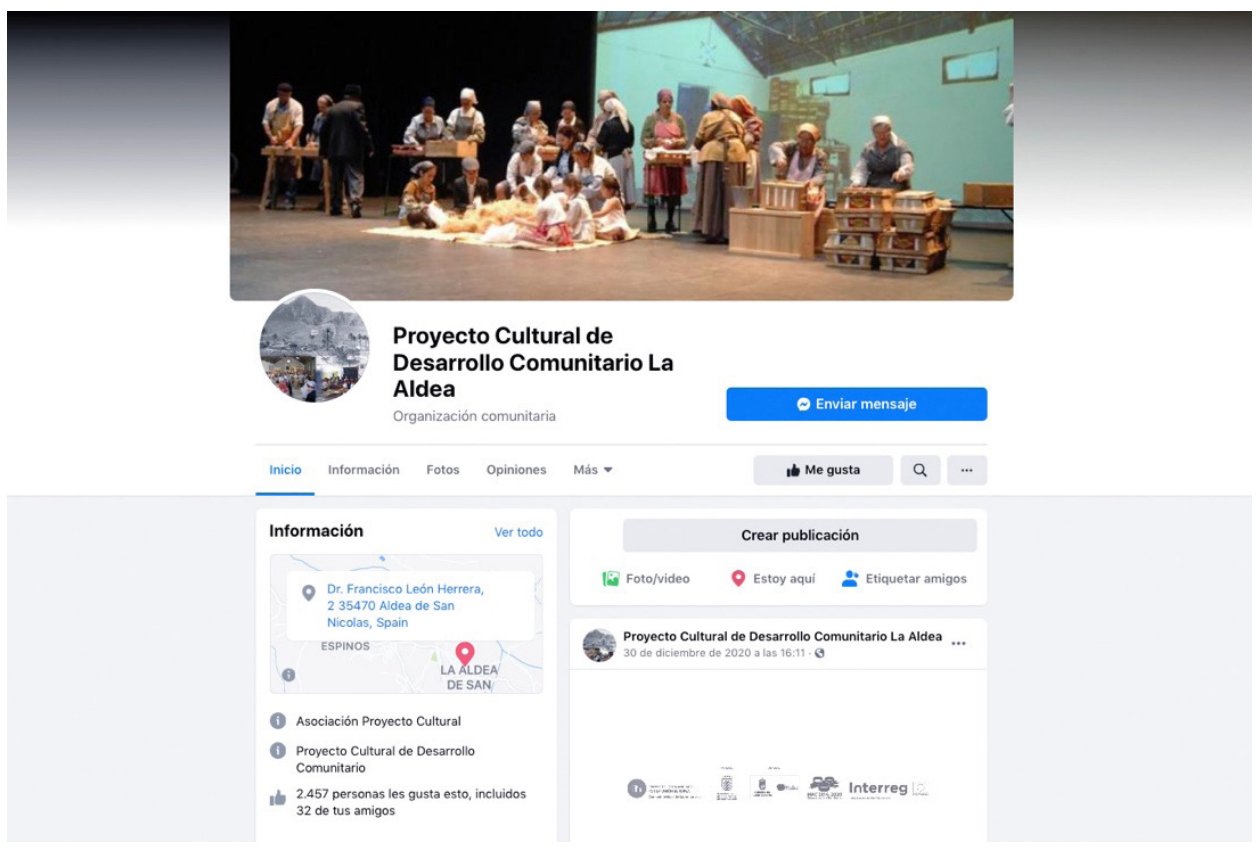

Figura 5. Página del Proyecto en Facebook [en línea]. Disponible en: https://www. facebook.com

Atendiendo a las entrevistas no estructuradas con los voluntarios y la observación directa, apreciamos que existe una importante relación de feedback en las redes sociales del Proyecto entre los voluntarios y los visitantes y entre los mismos voluntarios. La red social que mayores comentarios genera es Facebook en la que los voluntarios suelen intercambiar comentarios, principalmente relacionados con las visitas al Proyecto. Estas relaciones se incrementan entre los voluntarios cuando se generan intercambios de fotografías (ya sean actuales o antiguas), en las que aparecen ellos mismos, familiares o actividades realizadas en los museos en vivo. Otra de las redes sociales que crea vínculos entre voluntarios y visitantes es Youtube. Asiduamente se generan vídeos con las diferentes actividades del Proyecto (actuales o históricas), y en las que la gente del pueblo tiene un papel relevante, entremezclándose las labores del Proyecto con otros hechos históricos del municipio. 


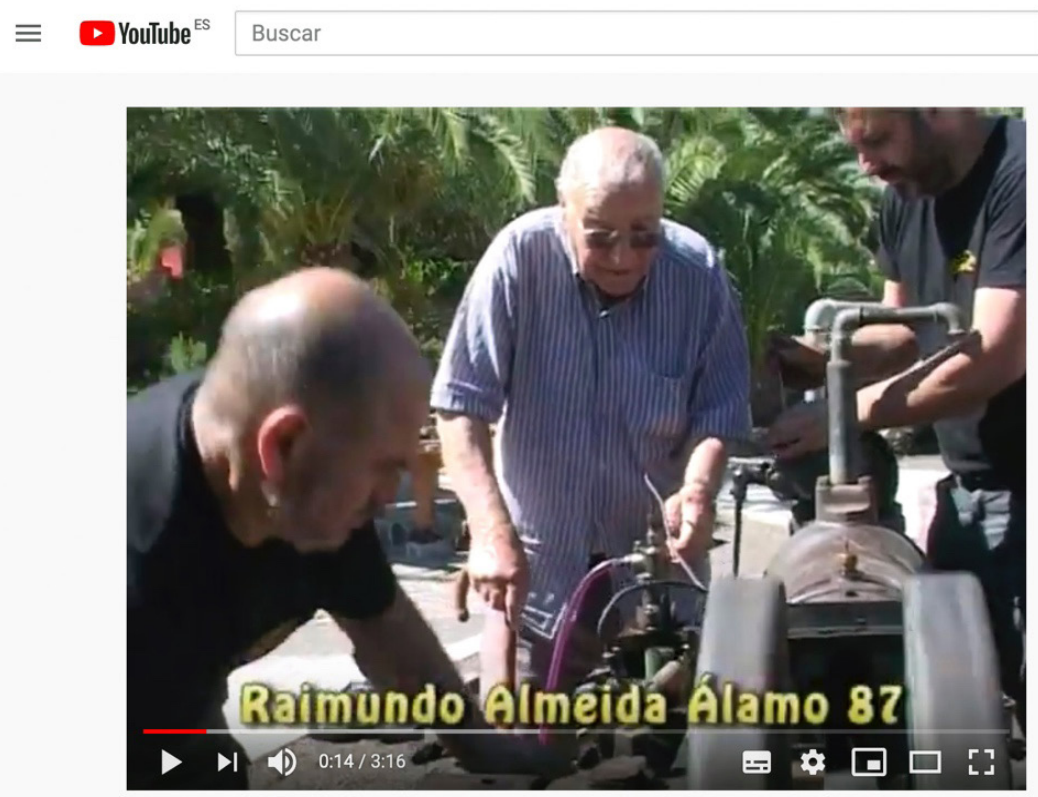

DOCUMENTAL INFORMANTES FALLECIDOS DEL PROYECTO COMUNITARIO LA ALDEA

473 visualizaciones. 7 may 2019 I 7 I $0 \Rightarrow$ COMPARTIR $\equiv+$ GUARDAR $\cdots$

Figura 6. Video en el canal del Proyecto en Youtube en línea].

Disponible en: www.youtube.com

Además de esta la promoción, el Proyecto obtiene visibilidad a través de su participación en diferentes eventos. Durante sus años de trayectoria, el Proyecto ha estado presente en diversos congresos de diferentes ámbitos (educación, turismo, museos, cultura, etnografía, etc.), teniendo una especial relevancia en los congresos de DEAC (Departamentos de Educación y Acción Cultural) de índole museística. Asimismo, ha generado interés en congresos internacionales de turismo, educación y cultura. Esa presencia en congresos, ferias, o actividades diversas, es normalmente expuesta online a través de los diferentes canales en los cuáles participa el Proyecto. Asimismo, se suelen involucrar activamente en la participación de cualquier actividad cultural o comercial que se genere desde las instituciones públicas en el municipio. De hecho, los museos se abren para el Mercadillo Municipal y para cualquier otro evento que solicite su colaboración. A ello se suma la visibilidad que reporta la existencia de un «boca a boca» casi siempre positivo.

Con todo ello, se ha garantizado la perdurabilidad del Proyecto. No obstante, a juicio de los voluntarios, la administración pública debiera hacer una mayor 
Beneficio social de los ecomuseos en el territorio. El Proyecto Cultural de Desarrollo...

promoción del mismo, no para cambiar el modelo de trabajo, basado en visitas a grupos reducidos, sino para darle una mayor sostenibilidad a lo largo del año.

\subsection{Los beneficios sociales del Proyecto}

A raíz de las encuestas y entrevistas realizadas, podemos establecer que el Proyecto está generando beneficios sociales en la población local de tres maneras diferenciadas. Por un lado, favorece la identificación de la población con la memoria histórica de La Aldea. Por otro, ha permitido que miembros de la comunidad de edad avanzada se sientan útiles participando en la transmisión de los valores etnológicos. Y, por último, ha estimulado la colaboración ciudadana en términos generales.

Todas estas consecuencias inciden directamente en el incremento de los niveles de cohesión social en el municipio, a lo que también colaboran los beneficios económicos que se generan. Los responsables del Proyecto, los voluntarios, y otros vecinos del municipio afirman que el Proyecto es un elemento que activa la economía y aumenta la visibilidad del municipio. Los grupos que visitan los radiales del Proyecto suelen comer en los restaurantes del pueblo, comprar productos locales y, en ocasiones, se alojan en el albergue municipal y en los hoteles del pueblo.

Aunque es complejo determinar y evaluar la cohesión social, como asî afirman los entrevistados, esta se ve incrementada, además de por un aumento en la concienciación identitaria del conjunto de la sociedad aldeana, por el desarrollo de una actitud de colaboración por buena parte de la sociedad. La cesión de inmuebles o la participación de personas ajenas a la asociación en actos puntuales es buena prueba de ello. Esta actitud colaboradora, sobre todo en la conservación de los radiales, se ha ido gestando gradualmente y a ello ha colaborado dos hechos fundamentales: el evidente altruismo de las personas que participan directamente en el Proyecto, lo que deriva en que familias enteras terminen colaborando en ocasiones con las actividades desarrolladas, y el carácter apolítico de la asociación. Sus miembros nunca se han involucrado en asuntos de interés político desde el Proyecto, lo que ha favorecido la participación de personas con ideologías y pensamiento político diferentes. En síntesis, según los informantes, el Proyecto ha proporcionado al municipio armonía, colaboración, participación y recuperación patrimonial.

En el análisis de los beneficios sociales nos interesa especialmente en lo que atañe a la generación de voluntariado. Con este fin se realizaron entrevistas en profundidad a 10 de los voluntarios más activos del Proyecto, todos ellos con edades comprendidas entre los 66 y 86 años, cuatro mujeres y seis hombres, todos jubilados. Los voluntarios suelen participar en las actividades que se realizan en los museos en vivo y en actos culturales, como hacer el pan o el queso, explicar la escuela, realizar labores en el almacén de empaquetado de tomates o participar en bailes y actuaciones musicales (Figura 7). 


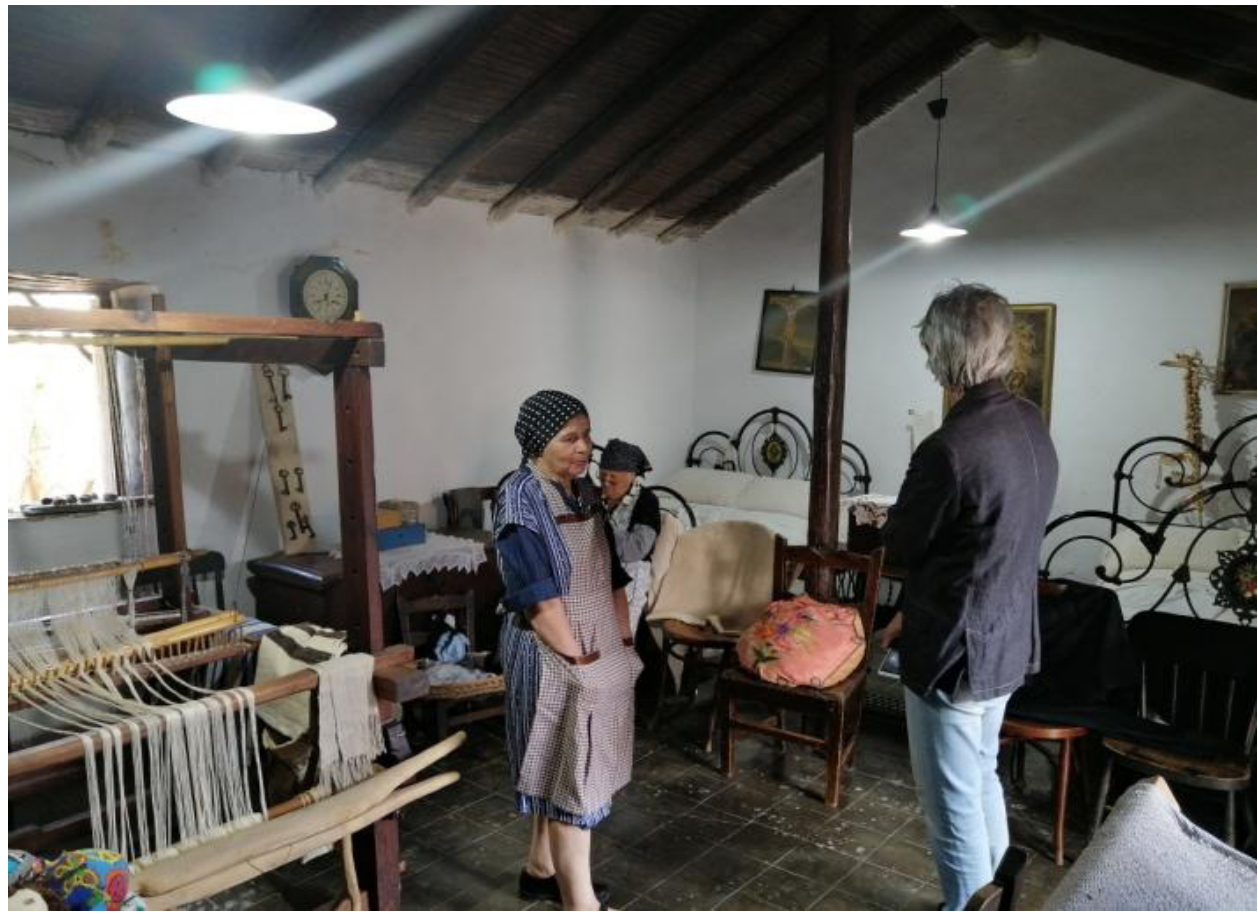

Figura 7. Voluntarias del Proyecto atendiendo una visita guiada.

Fotografía: Héctor Moreno, 2020.

Los entrevistados declaran que a nivel personal todo esto les ha reportado alegría, ganas de hacer cosas y entretenimiento. Muchos declaran sentir felicidad, orgullo, cariño o devoción por su labor en el Proyecto, así como no sentir obligaciones a la hora de participar. En general todos manifiestan sentirse útiles, ya que son conscientes que su aportación es clave para la recuperación de tradiciones perdidas o a punto de perderse. Manifiestan motivación como prueba que, en 1993, 80 voluntarios se hayan financiado ellos mismo un viaje a Cuba para realizar diversas actividades de tipo cultural. Por todo ello, declaran que el Proyecto les permite ganar en salud y tener vivencias de aprendizaje.

Pero además los entrevistados destacan que para ellos son fundamentales las relaciones que establecen con el resto de voluntarios y el sentimiento de pertenencia a un grupo. La totalidad de los participantes en la entrevista expresan que el Proyecto les ha permitido mantener amistades. Pero además sienten que forman parte de un grupo y que como tal son escuchados. El hecho de que cuando tienen alguna propuesta la puedan plantear en la asamblea, se debata y se busca un consenso para decidir es una práctica que refuerza la pertenencia al grupo. De ahí que todos los entrevistados declaren que les gusta la forma de gestión, así 
Beneficio social de los ecomuseos en el territorio. El Proyecto Cultural de Desarrollo...

como su deseo de mantener el modelo actual de funcionamiento.

En relación con esto, de las entrevistas realizadas se deriva que no ha habido conflictos de gravedad y los desacuerdos entre participantes se solucionan hablando y normalmente de manera rápida. El Proyecto, por tanto, favorece también, la cultura del diálogo, la empatía y la aceptación de la diversidad, aspectos necesarios para la cohesión social.

\subsection{El museo desde el punto de vista de los visitantes}

Los visitantes del Proyecto están en torno a los 4.600 (Tabla 2). Son mayoritariamente residentes, aunque hay una parte importante de no residentes. Las visitas son principalmente en grupo y previamente concertadas. Suelen ser guiadas, aunque también pueden hacerse de manera libre. Destacan las visitas de grupos de escolares y de colectivos específicos como asociaciones, organizaciones no gubernamentales, etc. -en grupos generalmente de 20 personas- (Figura 8), que llega por lo tanto a través de transporte colectivo discrecional.

TABLA 2

Distribución de los visitantes en el Proyecto Comunitario en 2019

\begin{tabular}{|c|c|c|c|c|c|}
\hline Total & $\begin{array}{c}\text { Escolares y } \\
\text { colectivos } \%\end{array}$ & $\begin{array}{c}\text { Insulares } \\
\%\end{array}$ & $\begin{array}{c}\text { Nacionales } \\
\%\end{array}$ & $\begin{array}{c}\text { Internacionales } \\
\%\end{array}$ & $\begin{array}{c}\text { Actividades } \\
\%\end{array}$ \\
\hline 4.600 & 55 & 15 & 10 & 15 & 5 \\
\hline
\end{tabular}

Fuente: Elaboración propia.

Las visitas que proceden del resto de la isla suelen ser a través de excursiones organizadas mientras que los visitantes que proceden del resto de territorio español llegan en grupos organizados o de manera libre. Los procedentes del extranjero normalmente visitan los museos en grupo, habiéndose concertado previamente con los turoperadores. Un pequeño porcentaje de los visitantes acuden a las actividades organizadas en el municipio, como ferias, congresos o actividades culturales. 

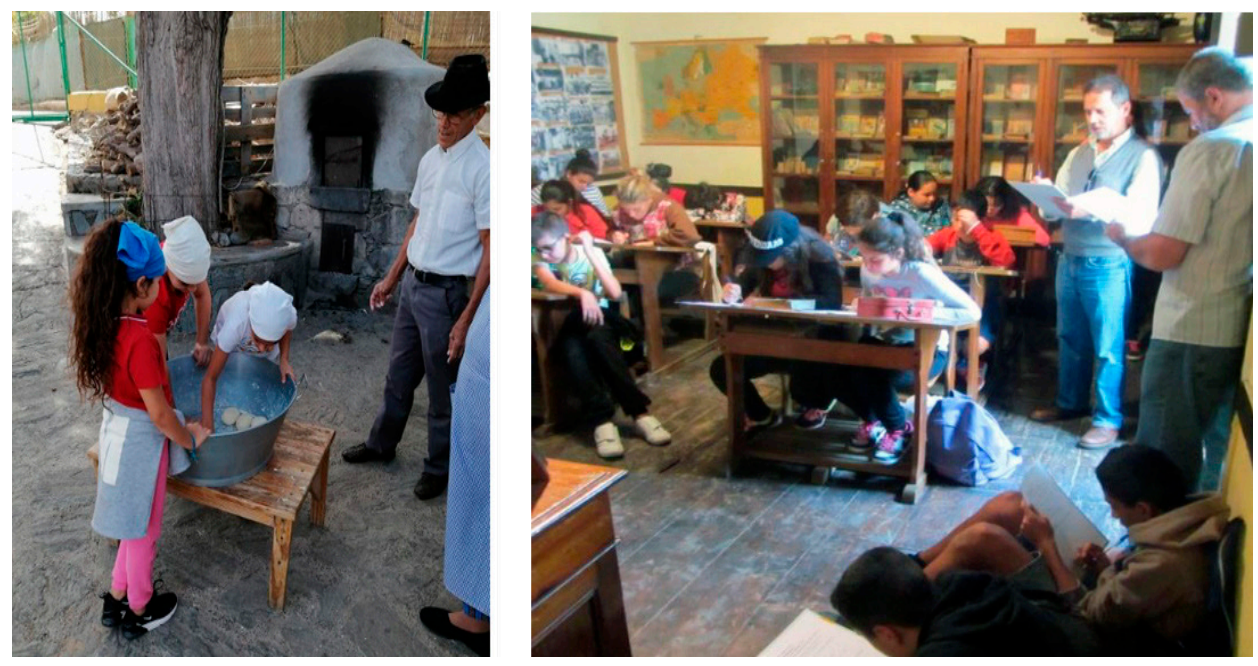

Figura 8. Jóvenes visitantes aprendiendo a hacer el pan (izquierda). Visita de estudiantes a la Escuela (derecha). Fotografía: Héctor Moreno, 2020 y 2014.

Tras los cuestionarios realizados a 100 visitantes (Tabla 3), podemos afirmar que los visitantes han conocido la existencia del Proyecto a través de una asociación o grupo colectivo, o de amigos o familiares, por lo que se determina que el Proyecto se publicita a través de los comentarios que se hacen los propios visitantes. Las motivaciones para la visita que destacan por los encuestados son «mejorar sus conocimientos» y conocer «uno de los principales atractivos culturales de la isla», por lo que se aprecia que el Proyecto tiene para los visitantes una dimensión vinculada al ocio y otra al ámbito educativo.

TABLA 3

Caracterización y opinión de los visitantes del Proyecto Comunitario de La Aldea

\begin{tabular}{|c|c|}
\hline Caracterización del visitante & $\begin{array}{l}\text { Proyecto Comunitario de La Aldea ( } \mathrm{n}=100) \\
\text { Total encuestados: } 100\end{array}$ \\
\hline Visitantes & $\begin{array}{c}\text { Escolares y colectivos: } 60 \%, \text { Insulares: } 15 \%, \\
\text { Nacionales: } 10 \% \text { e Internacionales: } 15 \% \\
9 \% \text { turistas / } 80 \% \text { residentes }\end{array}$ \\
\hline ¿Cómo llegan? & $75 \%$ excursión \\
\hline
\end{tabular}


Beneficio social de los ecomuseos en el territorio. El Proyecto Cultural de Desarrollo...

\begin{tabular}{|c|l|}
\hline Conocimiento del museo & $\begin{array}{c}\text { Asociación o grupo } \\
\text { Amigos y familiares }\end{array}$ \\
\hline Motivación destacada & «mejorar los conocimientos» 27\% \\
& «es uno de los principales atractivos»17\% \\
\hline Satisfacción (sobre 10) & 8.88 \\
\hline Comentarios libres & $\begin{array}{c}162 \text { comentarios: } 48 \text { sugerencias, } 101 \text { positivos } \\
\end{array}$ \\
\hline
\end{tabular}

Fuente: Elaboración propia.

Tratando de medir la satisfacción de la visita se solicitó a los encuestados calificar en una escala de Likert 10 una serie de aspectos (trato, ambiente, presentación, claridad y utilidad de contenidos, aprendizaje, interés, accesibilidad, señalización, entradas, servicios, esperas), obteniendo una media de 8,88. Los aspectos mejor valorados fueron el aprendizaje $(9,5)$ y el trato $(9,4)$, mientas que los peor valorados fueron la accesibilidad $(8,7)$ y los servicios $(6,5)$. Estos datos pueden, tomados de manera sistemática, contribuir a mejorar las encomiendas del Proyecto, dando voz a los visitantes.

Sin embargo, más destacable es el número y calidad de los comentarios o respuestas libres que muestran el interés de los visitantes por intervenir en el proceso de representación patrimonial. En esos comentarios libres se destaca la visión positiva del proyecto, con 101 comentarios y el bajo número de aportaciones negativas (13), estos últimos en ocasiones vinculados a aspectos ajenos al Proyecto.

Más allá de solicitar mejoras en los servicios como incluir restauración o tienda de suvenires en la oferta (algo que no deja de ser importante en estos contextos patrimoniales y de ocio), los visitantes indican que desean otros servicios, como, por ejemplo, una mejora en la comunicación de contenidos (vídeos y folletos). De hecho, el folleto disponible para público no escolar no reúne las características apropiadas para la comunicación de contenido patrimonial. El problema radica en la falta de profesionalización y medios para contar con un equipo responsable de la comunicación.

\section{CONCLUSIONES}

El presente trabajo concuerda con que el éxito de un museo no siempre está ligado a la rentabilidad económica del mismo. Es cierto que los museos necesitan financiarse para mantener su funcionamiento, pero no se puede medir el éxito a través del número de visitantes o la rentabilidad derivada de los ingresos percibidos. Gran parte del éxito de un ecomuseo deriva del impacto que se 
genera en la población local. Son diversos los aspectos que determinan el buen hacer que proyecta un ecomuseo en la sociedad, y se basan fundamentalmente en valores como la didáctica, la participación, la sostenibilidad, la implicación, la transparencia o la confianza.

Tras el análisis realizado en este estudio, se puede determinar que los principales procesos desarrollados en los ecomuseos comunitarios que se relacionan con beneficios sociales para las poblaciones en las que se desarrollan se basan principalmente en la buena relación entre los voluntarios, la comunicación con el público visitante (directa y online), la gestión responsable que ejerce el ecomuseo a la hora de atender a los agentes que se vinculan al mismo y la correcta distribución de responsabilidades en la gestión de la institución.

Se puede generalizar que uno de los pilares básicos en el buen funcionamiento de un ecomuseo es la relación de confianza entre los voluntarios y los coordinadores del mismo. Asimismo, es de destacar que se debería optimizar el principal atractivo que genera la visita al espacio (territorial, educativo, de ocio, etc.), y que para ello es necesario conocer de antemano la opinión del visitante acerca de los principales atractivos que conforman el centro museístico. ${ }^{12}$

De todo ello se derivan claros beneficios sociales. Este análisis coincide con el estudio de Bollo (2013), en el que se establece que el impacto social de los ecomuseos comunitarios incluye consecuencias sociales en áreas como salud, educación, inclusión social, revitalización urbana, etc. y la gama de posibles beneficios individuales derivados del compromiso con el museo (aprendizaje, disfrute, desarrollo personal, construcción de identidad, etc.). También se coincide con las determinaciones de MurAWSKI (2016), que considera que se materializa el derecho de toda persona a la participación significativa, se genera una experiencia más rica en el visitante y se produce debate continuo, conocimiento crítico o distinción local.

En el aspecto referente al beneficio específico que se genera a los voluntarios de un ecomuseo comunitario, esta investigación concuerda con el artículo de STAMER et al. (2008), que ayuda en la creación de comunidades de implicados más amplias, mejora las experiencias de aprendizaje de los voluntarios y fomenta la autogestión entre ellos. Asimismo, en este estudio se pueden corroborar las tendencias propuestas por CLARI (2012) en torno a la innovación digital que un ecomuseo puede ofrecer en cuanto a la relación con sus implicados, en las que el espacio digital como repositorio se transforma en un espacio digital como ambiente para el compromiso dialógico colectivo, o, dicho de otro modo, cómo los usuarios digitales pasan de ser visitantes o voluntarios de confianza a participantes, aprendices y comentadores. Siguiendo el mismo texto de referencia, se puede constatar también la transformación que se produce en los comisarios, en este caso concreto, los gestores del Proyecto, que pasan de ser editores y administradores a participantes, aprendices y comentadores.

GIANINNI y Bowen (2019: 4), afirmaban que los ecomuseos participativos se esfuerzan por mantener el ritmo del progreso en la tecnología digital. Esta

12 EVE Museos e Innovación: Museos y medición de éxito, 2016 [en línea]. Disponible en: https:// evemuseografia.com/2016/03/29/museos-y-la-medicion-del-exito [Consulta: 18/06/2020]. 
Beneficio social de los ecomuseos en el territorio. El Proyecto Cultural de Desarrollo...

aseveración se puede comprobar en el ejemplo del Proyecto, ya que existe una comunicación, participación activa e interacción digital creciente tanto entre los voluntarios del Proyecto, como entre éstos y sus visitantes, y con otros interesados (por ejemplo, vecinos del municipio). Se puede testificar que el uso de herramientas online impulsa el interés de los implicados, generándose una sinergia participativa en torno a los contenidos que genera el ecomuseo. De ahí se deduce que el ecomuseo comunitario se convierte en un instrumento de digitalización social.

Y, a todo ello se suman otros beneficios sociales como la creación de capacidad de diálogo entre los participantes, el fomento de la cultura de la gestión compartida, la valorización del patrimonio cultural local y de actitudes comprometidas al respecto, la generación de sentimientos identitarios o de sentimientos personales positivos, entre otros.

No obstante, los ecomuseos comunitarios presentan también importantes problemas. Aunque no se hayan destacado en el caso analizado, estos son principalmente la falta de ayudas económicas para realizar el mantenimiento de los museos, la pérdida de voluntarios y la gran dependencia de los colaboradores y líderes. Y en este sentido, las instituciones púbicas debieran apoyar este tipo de modelos con medidas más decididas sin que se interfiera en la lógica museística. En el caso del Proyecto analizado, sería de gran ayuda que la administración comprara los espacios privados y cediera su uso y gestión a la asamblea como estrategia de permanencia en el tiempo. El modelo, aunque está consolidado, se fortalecería de esta manera.

\section{REFERENCIAS}

Adie, B.A.; Hall, C.M. (2017): «Who visits World Heritage? A comparative analysis of three cultural sites», Journal of Heritage Tourism, 12 (1): 67-80.

BAtista PÉrez, M.V. (2009): «Ecomuseo Itinerante. Orígenes y Desarrollo», en M.V. BAtista (coord.), Taller Ecomuseo Itinerante. Integrando los elementos integrales del paisaje, Proyecto Editorial Arsdidas, La Palma: 12-16.

Bauman, Z. (2003): Comunidad. En busca de seguridad en un mundo hostil, Siglo XXI de España Editores, Madrid.

Bellaigue, M. (1993): «El ecomuseo como posible medio de integración», en R.C. Bonfil y N. García Canclini (eds.), Memorias del simposio: Patrimonio, Museo y Participación Social, INAH, Colección Científica, México, D.F.

Bollo, A. (2013): Measuring Museum Impacts. The Learning Museum Project, Bologna. Boyd, C. P y Hughes, R. (2020): «Museology, Cultural Geography, and Nonrepresentational», en C. Boyd y R. Hughes, Emotion and the Contemporary Museum: Development of a Geographically-Informed Approach to Visitor Evaluation, Palgrave Macmillan, Singapore: 1-9.

Clari, M. (2012): "In the hands of the user: a study of changing models of participation and learning around digital heritage collections», en 
Héctor Moreno Mendoza, Agustín Santana Talavera y Juan Manuel Parreño Castellano

S. Chryssoulakis, A. Bounia y D. Andriopoulou (eds), Museum Education and New Media (ICOM Education, 23), ICOM, Paris: 15-30.

Clausen, K., Carstensen, P. y Granum, M. I. (2015): «Rethinking the ecomuseum», en J.T. Jensen y I.B. LundgaArd (coords.), Museums: Citizens and sustainable solutions, Danish Agency for Culture, Copenhagen: 232-251.

Davis, P. (2008): «New museologies and the ecomuseum», en B. Graham y P. HowARD (eds.) The Ashgate Research Companion to Heritage and Identity, Ashgate , Burlington: 397-414.

Delgado Ruiz, M. (2005): «Espacio público y comunidad. De la verdad comunitaria a la comunicación generalizada», en M. LISBONA GUILLén (coord.), La comunidad a debate: reflexiones sobre el concepto de comunidad en el México contemporáneo, El Colegio de Michoacán AC y Universidad de Ciencias y Artes de Chiapas: 25-39.

Dogan, M. (2015): «Ecomuseum, community museology, local distinctiveness, Hüsamettindere village, Bogatepe village, Turkey», Journal of Cultural Heritage Management and Sustainable Development, 5 (1): 43-60.

Drouguet, N. (2016): «The Curator's Malaise with the "Undisciplined" Museum: Exhibition Making in the musée de société», THEMA. La revue des Musées de la civilisation, 4: 23-34.

FuLLER, N.J. (1992): «The museum as a vehicle for community empowerment: The Ak-Chin Indian community ecomuseum Project», en I. KarP, C. Kreamer y S. Levine (eds.), Museums and Communities: The politics of public Culure, Smithsonian Institution Press, Washington and London: 327-365.

GianninI, T.; Bowen, J.P. (2019): «Digital Culture», en T. GianninI, y J.P. Bowen (eds.), Museums and Digital Culture: New perspectives and research, Springer, Cham: 3-26.

GibBs, G. (2012): El análisis de datos cualitativos en Investigación Cualitativa, Ediciones Morata, Madrid.

GIL, I.B. (2012): «Papel del ecomuseo como elemento dinamizador del desarrollo rural», en O. DE COS y P. REQues (coords.), La población en clave territorial: procesos, estructuras y perspectivas de análisis, Ministerio de Economía, Industria y Competitividad, Santander: 192-197

Giroux, É. (2016): «The Public in Museums: Visitors or Citizen Partners?», THEMA. La revue des Musées de la civilisation, 4: 109-124.

GonZÁlez-VARAS, I. (2015): Patrimonio cultural: conceptos, debates y problemas, Cátedra, Madrid.

GUERRERO MuÑoz, J.F. (2012): «Interrelación del patrimonio cultural- comunidadterritorio», en A. VACCA y E. GARCía, Procesos del patrimonio cultural, El Colegio de Jalisco, Zapopan: 99-116.

Hubert, F. (1993): «Historia de los ecomuseos», en G.H. Rivière, La museología. Curso de museología/Textos y testimonios, Akal, Madrid: 195-216.

López García, J.S., dir. (2003): Norte de Gran Canaria. Guía de Patrimonio Cultural y Turismo Sostenible, Mancomunidad de Ayuntamientos del Norte de Gran Canaria, Las Palmas de Gran Canaria.

MAGGI, M. (2009): «Ecomuseums in Italy, concepts and practices», Museologıa e 
Beneficio social de los ecomuseos en el territorio. El Proyecto Cultural de Desarrollo...

\section{Patrimônio, 1 (2): 70-78.}

McCALL, V.; Gray, C. (2014): «Museums and the 'new museology': theory, practice and organisational change», Museum Management and Curatorship, 29 (1): 1935.

MurAWSKI, M. (2016): «The Urgency of Empathy and Social Impact in Museums», Journal of Folklore and Education, 3: 42-47

NAvAjas Corral, O. (2019): «Ecomuseums in Spain: an analysis of their characteristics and typologies», Muzeológia a kultúrne dedičstvo, 7 (1): 7-26.

Ognjević, T. (2017): «Power of museums lies in diversity», The National Committee Magazine, 7: 6-7.

Ormston, R.; SPEncer, L.; BARnARD, M.; SNAPE, D. (2014): «The foundations of qualitative research», en J. Ritchie, J. Lewis, C. McNaughton Nicholls y R. ORMSTON (eds.) Qualitative research practice: A guide for social science students and researchers, SAGE, Los Angeles: 1-23.

PATTON, M.Q. (2005): «Qualitative research», en B.S. EveritT y D. Howell (eds.), Encyclopedia of statistics in behavioral science, John Wiley \& Sons, vol. 3, Chichester.

PIRes, M.H. (2000): «Ecomuseo», en J. TeIXeIRA Coelho, Diccionario crítico de política cultural: cultura e imaginario, ITESO-CONACULTA, Guadalajara, Jalisco.

PocE, A. (2014): «Promoting science: the creation of a scientific observatory to raise awareness on sea biodiversity», en E. NARDI y C. AgNELINI (eds.), Best Practice 3. A tool to improve museum education internationally, Edizioni Nuova Cultura, Roma: 109-118.

Quintero, V.; SÁnchez-CARretero, C. (2017): «Los verbos de la participación social y sus conjugaciones: contradicciones de un patrimonio democratizador», Revista Andaluza de Antropología, 12: 48-69.

RivarD, R. (1988): «Museums and ecomuseums-questions and answers», en J.A. GJestrum y M. MAure (eds.), Okomuseumsboka-identitet, okologi, deltakelse, ICOM Norway, Tromso: 123-128.

RivièRe, G.H. (1985): «Définition évolutive de l'écomusée», Museum, 148: 182-183.

Ross, M. (2004): «Interpreting the new museology», Museum and Society, 2 (2): 84103.

SÁnchez, L.; SuÁrez J.P.; Moya, J. (2002): Proyecto comunitario de La Aldea: un compromiso con la cultura popular, Gobierno de Canarias, Santa Cruz de Tenerife.

SÁNCHEZ, L.; SuÁrez, J.P. (2006): «Rescatar el Patrimonio intangible: el proyecto comunitario de La Aldea de San Nicolás», Boletín de Patrimonio Histórico, 3-4: 46-49.

SANZ, M.G.; Torruella, M.F. (2015): «Educación patrimonial e identidad. El papel de los museos en la generación de cohesión social y de vínculos de pertenencia a una comunidad», Clío: History and History Teaching, 41: 1-10.

Simons, H. (2011): El estudio de caso: Teoría y práctica, Ediciones Morata, Madrid.

StAmer, D.; Lerdall, K.; GuO, C. (2008): «Managing heritage volunteers: An exploratory study of volunteer programmes in art museums worldwide», Journal of Heritage Tourism, 3 (3): 203-214. 
SuÁrez Moreno, F.; SuÁrez Pérez, A. (2005): Guía del patrimonio etnográfico de Gran Canaria, Cabildo de Gran Canaria, Las Palmas de Gran Canaria.

TELLIS, W. (1997): «Application of a case study methodology», The qualitative report, 3 (3): 1-19.

ThOMAS, G.; JAMES, D. (2006): «Reinventing grounded theory: some questions about theory, ground and Discovery», British Educational Research Journal, 32 (6): 767-795.

Vergo, P. (ed.) (1997): New museology, Reaktion books, London.

VV. AA. (2013): La experiencia de la visita al museo. Colección Conociendo a nuestros visitantes, Ministerio de Educación, Cultura y Deporte, Madrid.

YIN, R.K. (2017): Case study research and applications: Design and methods, SAGE, Thousand Oaks, CA. 
